Z sta edição de junho 2012 traz uma revisão sobre prognóstico de epilepsia em longo prazo e um artigo original sobre volume hipocampal e talâmico em dois grupos de pacientes com epilepsia de lobo temporal mesial - com e sem resposta adequada a drogas antiepilépticas (DAEs), mostrando que atrofia hipocampal ocorre também no grupo de pacientes com crises controladas e que a atrofia de tálamo ipsilateral ao foco epileptogênico está correlacionada com a idade dos pacientes.

Este número do JECN traz ainda o resumo expandido do trabalho vencedor do Prêmio Aristides Leão durante o Congresso Brasileiro de Epilepsia de 2012 em Ribeirão Preto, que demonstra a excelente qualidade dos jovens pesquisadores brasileiros na área de epileptologia.

Boa leitura!

\title{
Fernando Cendes
}

Editor, JECN 